\title{
Exigência de metionina + cistina total para codornas de corte em crescimento
}

[Total methyonine + cystine requirement for meat type quails during the growing phase]

\author{
G.S.S. Corrêa $a^{1,6}$, M.A. Silva ${ }^{2,6 *}$, A.B. Corrêa ${ }^{1}$, V. Almeida ${ }^{1}$, D.O. Fontes ${ }^{2}$, R.A. Torres ${ }^{3,6}$, \\ N.J.L. Dionello ${ }^{4}$, L.S. Freitas ${ }^{5}$, R.V. Ventura ${ }^{1}$, A.A. Paulo ${ }^{5}$, J.V. Silva ${ }^{5}$, G.G. Santos ${ }^{5}$ \\ ${ }^{1}$ Aluna de pós-graduação - EVUFMG - Belo Horizonte, MG \\ ${ }^{2}$ Escola de Veterinária - UFMG \\ ${ }^{3}$ Universidade Federal de Viçosa - Viçosa, MG \\ ${ }^{4}$ Departamento de Zootecnia - FAEM - UFPel - Pelotas, RS \\ ${ }^{5}$ Aluna de graduação EVUFMG - Belo Horizonte, MG \\ ${ }^{6}$ Bolsista do $\mathrm{CNPq}$
}

\begin{abstract}
RESUMO
Estudou-se a exigência de metionina + cistina total para codornas de corte em crescimento durante os períodos inicial (sete a 21 dias) e final ( 22 a 42 dias de idade). O delineamento experimental foi inteiramente casualizado, com cinco repetições de 13 codornas por unidade experimental. Os tratamentos consistiram de seis níveis de metionina + cistina total $(0,73 ; 0,79 ; 0,85 ; 0,91 ; 0,97$ e $1,03 \%)$. Foram estudadas as variáveis: ganho de peso $(\mathrm{g})$, peso final no período $(\mathrm{g})$, consumo de dieta $(\mathrm{g})$ e conversão alimentar (g de dieta/g de peso). As respostas de desempenho foram obtidas por meio de modelos de regressão linear e quadrática. Codornas de corte alimentadas com dietas contendo $0,95 \%$ de metionina + cistina total no período inicial (sete a 21 dias) e $0,73 \%$ de metionina + cistina total no período final ( 22 a 42 dias) de criação obtêm máximo ganho de peso.
\end{abstract}

Palavras-chave: codorna, exigência nutricional, aminoácido, ganho de peso, consumo alimentar, conversão alimentar

\begin{abstract}
Total methyonine + cystine requirements during the initial (7-21 days of age) and final period (22-42 days of age) of the growing phase were estimated for meat type quails in a completely randomized experimental design with six treatments, five replicates and 13 quails per experimental unit. Weight gain $(g)$, body weight $(g)$, feed consumption $(g)$ and feed : weight gain ratio $(g / g)$ were evaluated for quails fed on $.73, .79, .85, .91, .97$ and $1.03 \%$ methyonine + cystine diets. Meat type quails fed $.95 \%$ and $.73 \%$ methyonine + cystine diets during the initial (7-21days of age) and final period (22-42 days of age) of the growing phase show maximum weight gain.
\end{abstract}

Keywords: meat type quail, nutritional requirement, aminoacid, weight gain, feed consumption, feed : weight ratio

\section{INTRODUÇÃO}

As dietas de codornas de corte são formuladas com base em exigências nutricionais de outros países, como o NRC (Nutrient..., 1994), ou em extrapolações de valores nutricionais constantes nas tabelas de exigências para frangos de corte ou codornas de postura, as quais podem não ser

Recebido em 13 de outubro de 2005

Aceito em 14 de fevereiro de 2006

* Autor para correspondência (corresponding author)

E-mail: martinho@vet.ufmg.br 
adequadas para o máximo desempenho dessas aves.

As dietas para codornas são formuladas com base na proteína bruta, o que pode acarretar em consumo excessivo de aminoácidos essenciais, que, em excesso, geram incremento calórico, excreção de volume excessivo de ácido úrico e maior gasto de energia. Além disso, o excesso de aminoácidos circulantes no sangue pode provocar diminuição do consumo de dieta (Goulart, 1997).

As codornas de corte apresentam maiores pesos e taxas de crescimento que as de postura. Segundo Marks (1991), a correlação entre velocidade de crescimento e consumo de dieta é alta em várias aves domésticas, entre elas frangos e codornas de corte.

O uso de aminoácidos sintéticos permite a formulação de dietas com teores de proteína bruta inferiores aos recomendados nas tabelas de exigências nutricionais. Com isso, pode-se maximizar a utilização dos aminoácidos para síntese protéica e minimizar seu uso como fonte de energia favorecendo a obtenção do máximo desempenho animal.

A metionina é considerada aminoácido essencial para o crescimento das aves, por ser doadora de radicais metil, necessários à biossíntese de creatina, carnitina, poliaminas, epinefrina, colina e melatonina, que são componentes corporais fundamentais ao crescimento normal dos animais. Além disso, no organismo a metionina pode ser catabolisada à cistina, mas somente parte da cistina pode ser convertida em metionina. Esse catabolismo tem funções de remover o excesso de metionina e superar a deficiência de cistina (Graber et al., 1971). A cistina participa da estrutura de muitas proteínas, como insulina, imunoglobulinas e queratina, interligando cadeias polipeptídicas por ponte dissulfeto (Baker, 1991). A metionina é o primeiro aminoácido limitante para aves que recebem dietas à base de milho e soja, ingredientes que compõem as dietas tradicionais de aves no Brasil.

O objetivo deste experimento foi estimar as exigências de metionina + cistina total para codornas de corte durante a fase de crescimento.

\section{MATERIAL E MÉTODOS}

Utilizaram-se 390 codornas européias de corte, de ambos os sexos, dos sete aos 42 dias de idade, com peso médio inicial de $25,05 \mathrm{~g}$.

O delineamento experimental foi o inteiramente ao acaso, com seis níveis de metionina total $(0,73 ; 0,79 ; 0,85 ; 0,91 ; 0,97$ e $1,03 \%)$ e cinco repetições, com 13 aves por unidade experimental. As aves foram submetidas à dieta basal (Tab. 1) formulada à base de milho e farelo de soja, contendo $23,9 \%$ de proteína bruta $(\mathrm{PB})$ e $2900 \mathrm{kcal}$ de $\mathrm{EM} / \mathrm{kg}$ de dieta, e de $0,73 \%$ de metionina mais cistina. A dieta basal foi suplementada com cinco níveis de DL-metionina (99\%), em substituição ao amido de milho, correspondendo aos níveis de 0,73 (dieta basal sem suplementação); 0,$79 ; 0,85 ; 0,91 ; 0,97 \mathrm{e}$ $1,03 \%$ de metionina mais cistina total, permanecendo as dietas isocalóricas e isoprotéicas.

Tabela 1. Composição percentual e calculada da dieta basal para codornas em crescimento

\begin{tabular}{|c|c|}
\hline Ingrediente & $\%$ \\
\hline Milho & 53,5 \\
\hline Farelo de soja & 41,9 \\
\hline Calcário & 1,07 \\
\hline Óleo de soja & 1,02 \\
\hline Fosfato bicálcico & 0,96 \\
\hline Amido & 0,50 \\
\hline Suplemento mineral e vitamínico ${ }^{1}$ & 0,50 \\
\hline Sal comum & 0,26 \\
\hline L-treonina & 0,26 \\
\hline \multicolumn{2}{|l|}{ Composição calculada } \\
\hline Proteína bruta (\%) & 23,89 \\
\hline Energia metabolizável (kcal/kg) & 2.90 \\
\hline Cálcio $(\%)$ & 0,80 \\
\hline Fósforo disponível (\%) & 0,30 \\
\hline Sódio (\%) & 0,15 \\
\hline \multicolumn{2}{|l|}{ Aminoácido total } \\
\hline Lisina (\%) & 1,30 \\
\hline Metionina + cistina $(\%)$ & 0,73 \\
\hline Treonina $(\%)$ & 1,19 \\
\hline Triptofano $(\%)$ & 0,30 \\
\hline Metionina (\%) & 0,46 \\
\hline Arginina $(\%)$ & 1,61 \\
\hline Isoleucina $(\%)$ & 1,04 \\
\hline Valina $(\%)$ & 1,11 \\
\hline \multicolumn{2}{|c|}{ 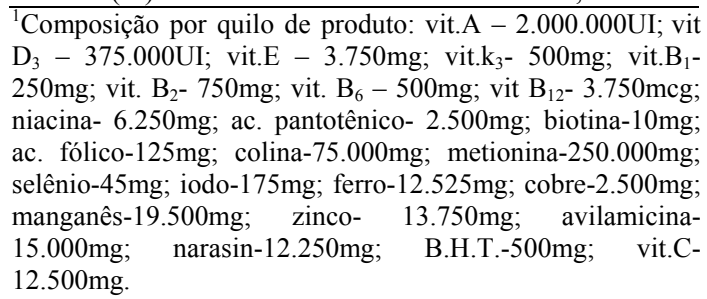 } \\
\hline
\end{tabular}


As dietas foram formuladas com base nas informações nutricionais de composições dos ingredientes apresentadas por Rostagno et al. (2000) e as exigências nutricionais de codornas em crescimento, constantes no NRC (Nutrient..., 1994), exceto para proteína bruta e metionina + cistina. Para todos os outros aminoácidos, as relações propostas pelo NRC (Nutrient...,1994) foram mantidas por intermédio da suplementação de aminoácidos sintéticos (DL- metionina) em substituição ao amido de milho, a partir da dieta base.

O programa de luz adotado foi o contínuo (24 horas de luz natural + artificial) durante todo o período experimental, e as dietas foram fornecidas à vontade.

As variáveis estudadas foram: peso $(\mathrm{g})$, ganho de peso $(\mathrm{g})$, consumo de ração $(\mathrm{g})$ e conversão alimentar ( $\mathrm{g}$ de ração/g de peso) nas fases de sete a 21 dias e de 22 a 42 dias de idade.

As análises estatísticas foram realizadas por meio do programa SAEG (Sistema..., 2004). A estimativa das exigências em metionina + cistina para cada período foi estimada por meio de equações de regressão polinomiais, respeitandose a interpretação biológica das variáveis.

\section{RESULTADOS E DISCUSSÃO}

Os níveis de metionina + cistina total da ração influenciaram $(\mathrm{P}<0,05)$ de forma quadrática no peso final e no ganho de peso das aves (Tab. 2), que aumentaram até os níveis estimados de $0,95 \%$, correspondentes à relação de metionina + cistina:lisina total de 0,73 , indicados pelas equações quadráticas $\hat{\mathrm{Y}}=135,093+541,424 \mathrm{X}-$ $285,893 X^{2}$ e $\hat{Y}=-151,623+522,268 X-$ $275,278 \mathrm{X}^{2}$, para o máximo peso final e ganho de peso, respectivamente (Fig. 1 e 2). Resultados semelhantes foram observados por Torres et al. (2005a e b), que encontraram aumento no peso de codornas de corte alimentadas com nível de $0,95 \%$ e $0,96 \%$ de metionina + cistina total, respectivamente, durante a fase inicial de criação. Corrêa et al. (2005) observaram, por meio de regressão linear, que codornas de corte alimentadas com dietas contendo $1,09 \%$ de metionina + cistina total apresentaram maior peso aos 21 dias de idade, e Pinto et al. (2003a) sugerem o nível de $0,86 \%$ de metionina + cistina em dietas para maior peso de codornas japonesas em crescimento. Entretanto, Arscott e PiersonGoeger (1997), Belo (1987) e Pinto et al. (2003b) não verificaram efeito dos níveis de aminoácidos sulfurados sobre o peso final das codornas de postura.

Tabela 2. Peso final, ganho de peso, consumo de ração e conversão alimentar das codornas de corte de sete a 21 dias de idade, segundo o nível de metionina + cistina da dieta

\begin{tabular}{lcccc}
\hline Nível de metionina & $\begin{array}{c}\text { Peso final } \\
(\mathrm{g})\end{array}$ & $\begin{array}{c}\text { Ganho de peso } \\
(\mathrm{g})\end{array}$ & $\begin{array}{c}\text { Consumo de ração } \\
(\mathrm{g})\end{array}$ & $\begin{array}{c}\text { Conversão alimentar } \\
(\mathrm{g} / \mathrm{g})\end{array}$ \\
\hline 0,73 & 106,580 & 81,690 & 187,970 & 2,304 \\
0,79 & 116,012 & 90,968 & 192,664 & 2,121 \\
0,85 & 118,968 & 94,016 & 194,006 & 2,067 \\
0,91 & 120,942 & 95,574 & 191,310 & 2,009 \\
0,97 & 118,544 & 93,438 & 199,904 & 2,143 \\
1,03 & 120,732 & 95,764 & 197,794 & 2,068 \\
CV & 3,77 & 3,21 & 7,02 & 8,64 \\
Significância & $*$ & $*$ & ns & ns \\
& \multicolumn{4}{c}{ Equação de regressão } \\
Peso final & $\hat{\mathrm{Y}}=135,093+541,424 \mathrm{X}-285,893 \mathrm{X}^{2}$ & $\left(\mathrm{R}^{2}=0,91\right)$ & 0,95 \\
Ganho de peso & $\hat{\mathrm{Y}}=-151,623+522,268 \mathrm{X}-275,278 \mathrm{X}^{2}$ & $\left(\mathrm{R}^{2}=0,90\right)$ & 0,95 \\
\hline
\end{tabular}

*=significativo; ns=não significativo. 


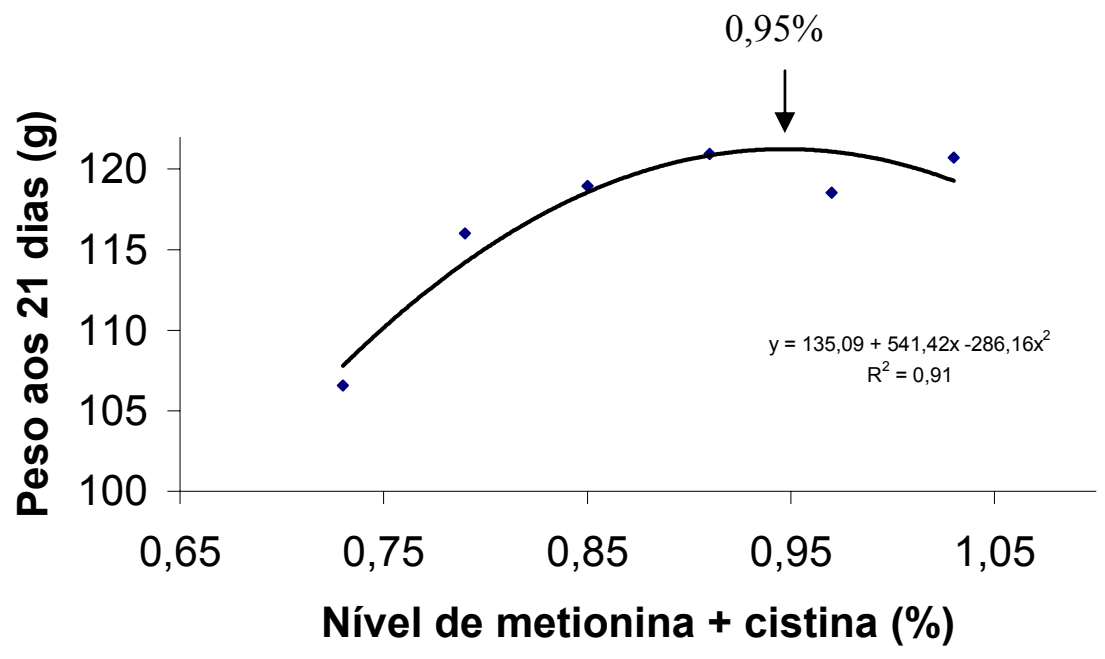

Figura 1. Regressão do peso vivo aos 21 dias de idade de codornas de corte em relação ao nível de metionina + cistina total da dieta.

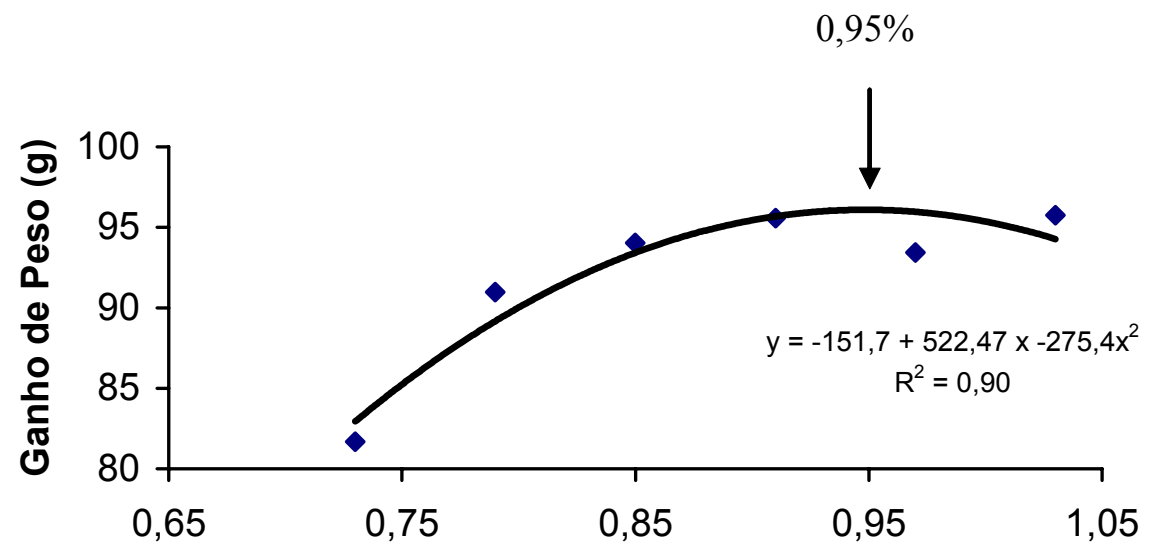

Nível de metionina + cistina (\%)

Figura 2. Regressão do ganho de peso de codornas de corte dos sete aos 21 dias de idade em relação ao nível de metionina + cistina total das dietas.

$\mathrm{O}$ peso médio das codornas neste experimento foi $116,96 \mathrm{~g}$ aos 21 dias, enquanto codornas japonesas de postura atingem peso médio de $87 \mathrm{~g}$ nessa idade. Portanto, altas concentrações de aminoácidos nas dietas são necessárias para rápido crescimento das codornas de corte, caracterizado, principalmente, pela formação de tecido protéico.

O nível de metionina + cistina total, que proporcionou a melhor resposta de ganho de peso neste estudo, ficou acima dos preconizados pelo NRC (Nutrient.., 1994) e por Svacha et al. (1970) para codornas japonesas em crescimento, que correspondem a 0,75 e $0,73 \%$ de metionina + cistina total, numa relação de 0,58 e 0,54 com a lisina total, respectivamente. Isso ocorre porque as codornas européias apresentam maior peso e maior taxa de crescimento comparadas às codornas japonesas.

Os níveis de metionina + cistina total não influenciaram $(\mathrm{P}>0,05)$ o consumo e a conversão alimentar (Tab. 2). Estes resultados indicam que 
o aumento nos níveis de metionina + cistina não foram suficientes para produzir imbalanço aminoacídico que resultasse na alteração do perfil plasmático do animal e que ativasse os mecanismos reguladores do apetite, como descrito por Harper et al. (1970).

Estes resultados foram semelhantes aos encontrados por Torres et al. (2005a), que não encontraram efeitos dos níveis de metionina + cistina sobre o consumo e a conversão alimentar de codornas de corte durante a fase inicial de criação, e por Murakami et al. (1994) e Stringhini et al. (1995), que não observaram efeito significativo dos níveis de aminoácidos sulfurados sobre o consumo alimentar das codornas japonesas. Possivelmente para esta variável, a exigência se encontre abaixo do menor nível testado, conforme encontrado por Pinto et al. (2003b), que observaram nível ótimo de $0,69 \%$ de aminoácidos sulfurados para consumo alimentar, porém não observaram efeito significativo desses aminoácidos sobre a conversão alimentar de codornas japonesas.

Houve efeito $(\mathrm{P}<0,05)$ do nível de aminoácidos sobre o ganho de peso das codornas dos 22 a 42 dias de idade (Tab. 3 e Fig. 3), que diminuíram de forma linear, conforme equação $\hat{Y}=167,713-$ $41,589 X$. Quanto maior o peso corporal, mais alimento é necessário para fornecer energia para mantença, restando pequena fração de energia para síntese de proteína. As exigências de aminoácidos, constituintes das proteínas, devem diminuir com o avanço da idade, em função principalmente da redução do ganho de peso. Torres et al. (2005b) não observaram efeito dos níveis de metionina + cistina total em codornas de corte no período de 22 a 42 dias de idade.

Tabela 3. Peso final, ganho de peso, consumo de ração e conversão alimentar das codornas de corte de 22 a 42 dias de idade, segundo o nível de metionina + cistina da dieta

\begin{tabular}{|c|c|c|c|c|}
\hline Nível de metionina & $\begin{array}{l}\text { Peso final } \\
(\mathrm{g})\end{array}$ & $\begin{array}{c}\text { Ganho de peso } \\
(\mathrm{g})\end{array}$ & $\begin{array}{l}\text { Consumo de ração } \\
(\mathrm{g})\end{array}$ & $\begin{array}{c}\text { Conversão alimentar } \\
(\mathrm{g} / \mathrm{g})\end{array}$ \\
\hline 0,73 & 240,512 & 133,932 & 573,232 & 4,287 \\
\hline 0,79 & 257,174 & 141,162 & 558,662 & 3,962 \\
\hline 0,85 & 249,312 & 130,344 & 576,596 & 4,432 \\
\hline 0,91 & 247,834 & 126,892 & 562,320 & 4,437 \\
\hline 0,97 & 249,804 & 131,260 & 563,348 & 4,299 \\
\hline 1,03 & 243,828 & 123,096 & 543,508 & 4,426 \\
\hline $\mathrm{CV}$ & 2,63 & 5,52 & 4,85 & 5,82 \\
\hline Significância & ns & $*$ & $\begin{array}{c}\text { ns } \\
\text { ăo de regressão }\end{array}$ & ns \\
\hline Ganho de peso & & $\hat{\mathrm{Y}}=167$ & $-41,589 \mathrm{X} \quad\left(\mathrm{R}^{2}=0,57\right)$ & \\
\hline
\end{tabular}

*=significativo; ns=não significativo

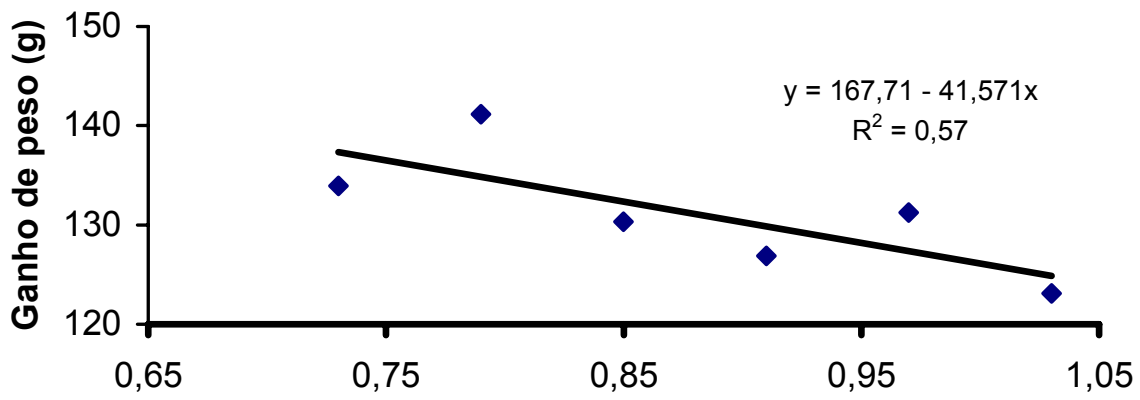

Nível de metionina + cistina(\%)

Figura 3. Regressão do ganho de peso de 22 a 42 dias de idade de codornas de corte em relação ao nível de metionina + cistina total das dietas. 
Não foi verificado efeito dos níveis de metionina + cistina sobre o consumo e a conversão alimentar (Tab. 3). Isso provavelmente se deveu ao fato de os aminoácidos testados estarem acima da exigência estabelecida para esta fase, caracterizada por menor taxa de ganho de peso, quando comparada à fase inicial. Cabe ressaltar que, mesmo com o menor nível de metionina + cistina testado $(0,73 \%), \quad$ as codornas apresentaram bom desempenho.

O nível de $0,73 \%$ de metionina + cistina total foi citado por Torres et al. (2005b) para codornas de corte durante a fase de 22 a 42 dias de idade. Weeler e Lashaw (1981) relatam que o aumento do nível de metionina + cistina favorece o peso corporal e diminui o consumo alimentar de frangos. Isto porque altos níveis de metionina + cistina são necessários para máxima eficiência de crescimento, pois aves que recebem dietas contendo baixos níveis de metionina + cistina podem apresentar maior consumo de alimento para atender o máximo crescimento, o que resulta em decréscimo na sua utilização.

Schava et al. (1970), ao estudarem as exigências nutricionais em lisina, metionina e glicina total para codornas japonesas em dois períodos de crescimento ( 0 a 3 e 4 a 5 semanas de idade), verificaram que, no primeiro período, foram necessários $1,4 \%$ de lisina, $0,74 \%$ de aminoácidos sulfurados e 1,7\% de glicina e, no segundo período, os níveis de $1,2 \%$ de lisina, $0,7 \%$ de aminoácidos sulfurados e $1,2 \%$ de glicina.

Portanto, considerou-se apenas o ganho de peso na fase final de criação para estabelecer a exigência nutricional de metionina + cistina de codornas de corte, uma vez que as variáveis consumo e conversão alimentar não foram influenciadas significativamente pelos níveis desses aminoácidos.

\section{CONCLUSÃO}

Os níveis de metionina + cistina total que propiciaram o maior ganho de peso para codornas de corte em crescimento foram $0,95 \%$ na fase inicial (sete a 21 dias) e $0,73 \%$ na fase final (22 a 42 dias de idade).

\section{REFERÊNCIAS BIBLIOGRÁFICAS}

ARSCOTT, G.H.; PIERSON-GOEGER, M. Protein needs for laying Japonese quail as influenced by protein level and aminoacid suplementation. Nutr. Rep. Int., v.24, p.12871295, 1981.

BAKER, D.H. Partitioning of nutrients for growth and other metabolic functions. Poult. Sci., v.70, p.1797-1805, 1991.

BALDINI, J.T.; ROBERTS, R.E.; KIRKPATRICK, C.M. Low protein rations for the Bobwhite quail. Poult. Sci., v.32, p.945-949, 1953.

BARBOSA, J.R. Exigência de metionina + cistina para frangos de corte na fase de crescimento e acabamento. 1998. 84f. Dissertação (Mestrado em Nutrição de Monogástricos) - Universidade Federal de Viçosa, Viçosa, MG.

BELO, M.T.S. Niveis de enrgia metabolizável e de metionina em rações de codornas japonesas (Coturnix coturnix japonica) na fase inicial de postura. 1997. 80f. Dissertação (Mestrado em Nutrição de Monogástricos) - Universidade Federal de Lavras, Lavras, MG.

CORRÊA, G.S.S.; SILVA, M.A.; CORRÊA, A.B. et al. Níveis de metionina + cistina para híbridos EV1 de codornas européias no período de crescimento. In: REUNIÃO ANUAL DA SOCIEDADE BRASILEIRA DE ZOOTECNIA, 42., 2005. Goiânia. Anais... Goiânia, GO: SBZ, 2005a. CD.

GOULART, C.C. Exigência nutricional de lisina para poedeiras leves e semipesadas. 1997. $51 \mathrm{f}$. Dissertação (Mestrado em Zootecnia) Universidade Federal de Viçosa, Viçosa, MG.

GRABER, H.G.; SCOTT, H.M.; BACKER, D.H. Sulfur amino acid nutrition of the growing chick: Effect of age on capacity of cystine to sparl dietary methinine. Poult. Sci., v.50, p.1450-1455, 1971

HARPER, A.E.; BENEVENGA, N.J.; WOHLHUETER, R.M. Effects of ingestion of disproportionate amounts of amino acids. Physiol. Rev., v.50, p.428-558, 1970.

MARKS, H.L. Feed efficiency changes accompanying selection for body weight in 
chickens and quail. World's Poult. Sci., v.47, p.197-212, 1991.

MURAKAMI, A.E.; FURLAN, A.C.; TATEISHI, A. et al. Exigência de metionina para codornas Japonesas (Coturnix coturnix japonica) em postura. In: REUNIÃO ANUAL DA SOCIEDADE BRASILEIRA DE ZOOTECNIA, 31., 1994, Maringá. Anais... Maringá, PR: SBZ, p.64.

NUTRIENT requeriments of poultry. Washington: National Academy of Sciences, 1994. p.44-45.

PINTO, R.; DONZELE, J.L.; FERREIRA, A.S. et al. Exigência de metionina mais cistina para codornas Japonesas em postura. Rev. Bras. Zootec., v.32, p.1166-1173, 2003a.

PINTO, R.; FERREIRA, A.S.; DONZELE, J.L. et al. Exigência de metionina mais cistina para codornas Japonesas em crescimento. Rev. Bras. Zootec., v.32, p.1174-1181, 2003b.

ROSTAGNO, H.S.; ALBINO, L.F.T.; DONZELE, J.L. et al. Composição de alimentos $e$ exigências nutricionais: Tabelas brasileiras. Viçosa, MG: Universidade Federal de Viçosa, 2000. 141p.

SISTEMA de análises estatísticas e genéticas SAEG. Versão 9.0. Viçosa, MG: UFV, 1999.

STRINGHINI, J.H.; CAFÉ, M.B.; MOGYCA, N.S. et al. Níveis de energia metabolizável e metionina para codornas japonesas em postura (Coturnix coturnix japonica). In: CONFERÊNCIA APINCO DE CIÊNCIA E TECNOLOGIA AVÍCOLA, 13., 1995, Campinas. Anais... Campinas: FACTA, 1995. p.125-126.

SVACHA, A.; WEBER, C.W.; REID, B.L. Lysine, methionine and glycine requirements of Japanese quail to five weeks of age. Poult. Sci., v.49, p.54-59, 1970

TORRES, R.A.; CORRÊA, G.S.S.; SILVA, M.A. et al. Desempenho de codornas EV2 para corte alimentadas com dietas com diferentes níveis de metionina + cistina durante a fase inicial. In: REUNIÃO ANUAL DA SOCIEDADE BRASILEIRA DE ZOOTECNIA, 42., 2005a. Goiânia. Anais... Goiânia, GO: SBZ, 2005a. CD.

TORRES, R.A.; CORREAA, G.S.S.; SILVA, M.A. et al. Exigência de metionina + cistina em híbridos EVH2 de codornas de corte durante a fase de crescimento. In: REUNIÃO ANUAL DA SOCIEDADE BRASILEIRA DE ZOOTECNIA, 42., 2005b. Goiânia. Anais... Goiânia, GO: SBZ, 2005b. CD.

WHEELER, K.B.; LATSHAW, J.D. Sulfur amino acid requirements and interactions in broilers during two growth periods. Poult. Sci., v.60, p.228-236, 1981. 